\title{
EL CONTRATO FORMALMENTE CIVIL DE PRESTACIÓN DE SERVICIOS COMO SUPUESTO DE APLICACIÓN DEL ORDEN PÚBLICO LABORAL. CERTEZA Y JUSTICIA EN LA EXCEPCIÓN A LA IGUALDAD ANTE LA LEY*
}

\author{
MAURICIO HORMAZÁBAL VALDÉS ${ }^{* *}$ \\ Abogado
}

\begin{abstract}
RESUMEN: El artículo octavo, inciso primero, del Código del Trabajo dispone que "toda prestación de servicios en los términos señalados en el artículo anterior, hace presumir la existencia del contrato de trabajo". Si bien es cierto este precepto se ha interpretado tradicionalmente como una presunción de relación laboral cuando se identifican los elementos esenciales del contrato de trabajo, en el presente ensayo se otorga una reinterpretación de tal inciso, mediante una reformulación del principio de primacía de la realidad desde un foco en las formalidades a un acento en las circunstancias socioeconómicas, pasando, entonces, desde una presunción de laboralidad a una presunción de afectación de libertad jurídica mínima para contratar con igual libertad. Se concluye que el mencionado artículo octavo tiene como función hacer excepción al artículo 1560 del Código Civil, evitándose con esta reinterpretación riesgos de revisión judicial y, principalmente, otorgando una interpretación y argumentación en Derecho para determinar si el contrato civil que se conoce constituye o no un supuesto de aplicación del orden público laboral.
\end{abstract}

Palabras clave: Calificación contractual, Principio de primacía de la realidad, subordinación y/o dependencia, libertad contractual, presunción de laboralidad, doctrina de los actos propios, error esencial, igualdad ante la ley, revisión judicial.

\begin{abstract}
The eighth article, first paragraph, of the Labour Code provides that "every provision of services under the terms stated in the previous article seems to suggest the existence of an employment contract." Although this provision has been traditionally interpreted as a presumption of employment when they identify the essential elements of the employment contract, in this essay is given a reinterpretation of such subsection, by a reformulation of the principle of primacy of reality from a focus on the formalities to an emphasis on socio-economic circumstances, passing, then, from a presumption of labor involvement to a presumption of minimum legal freedom for contract with equal freedom. We conclude that the eighth article has the function to make an exception to the Article 1560 Civil Code, thus avoiding this reinterpretation risk of judicial review and, mainly, giving an interpretation and argumentation in law to determine whether the civil contract is or not is an assumption of the application of public policy work.
\end{abstract}

Key words: Rating contractual principle of primacy of reality, subordination and / or dependence, freedom of contract, the presumption of workind patterns, doctrine from the acts proper, fundamental error, equality before the law, judicial review.

\footnotetext{
Este trabajo es parte integrante de la investigación realizada para optar al grado académico de magíster titulada "La Unidad del Derecho como defensa de las expectativas del empleador en la aplicación del orden público laboral".

** Abogado, Magíster en Derecho, Abogado Superintendencia Electricidad y Combustibles. Correo electrónico: mauriciohormazabalv@gmail.com
} 
Mauricio Hormazábal Valdés / El contrato formalmente civil de prestación de servicios como supuesto de aplicación del orden priblico laboral...

\section{INTRODUCCIÓN}

En los últimos años la doctrina laboralista ${ }^{1}$ ha mostrado preocupación por una serie de fallos de nuestra Corte Suprema ${ }^{2}$ que resuelve controversias con pretensiones laborales, teniendo presente varios elementos que la doctrina civil históricamente ha catalogado como doctrina de los actos propios ${ }^{3}$, principalmente, por consideraciones de buena fe ${ }^{4}$. Ahora bien -hacemos la prevención-, no es propósito de este trabajo entrar a conocer y explicar la construcción dogmática de los actos propios o si en los casos que se ha pronunciado la Corte Suprema es admisible tal categoría, pero sí lo es preguntarse desde ya por qué nuestro máximo Tribunal resuelve sin cobertura normativa laboral positiva y sin argumentación jurídico laboral una controversia que se plantea en sede laboral.

En este sentido, y para efectos de delimitar nuestro trabajo, declaramos que el problema de nuestra Corte Suprema atiende principalmente a razones de buena fe, entendida esta como "un arquetipo o modelo de conducta social: la lealtad en los tratos y el proceder honesto, esmerado y diligente; la fidelidad a la palabra dada, en definitiva, no defraudar la confianza que objetivamente se ha suscitado a los demás, ni abusar de ella"s. Buena fe que ha resultado determinante a la hora de aplicar el orden público laboral, concreta y únicamente cuando se enfrenta a una relación duradera, nominalmente civil, con bajo estándar de subordinación y con conductas evidentes del pretensor que se beneficia de la aparente relación civil, por lo tanto, con pleno conocimiento durante el desarrollo de la relación contractual de las expectativas legítimas de las partes.

En este sentido, se ofrece una línea argumentativa laboral y una cobertura normativa jurídico laboral, que permitirá a los órganos decisores resolver conforme a Derecho y de acuerdo con categorías dogmáticas propias del Derecho del Trabajo, con el fin de responder a las exigencias necesarias que el Derecho positivo impone para el desenvolvimiento de la modernidad, pero sin excluir la justicia material, en casos tan difíciles como el planteado más arriba.

En este orden de ideas, para efectos de cumplir tal meta, es necesario reformular el principio jurídico laboral de la primacía de la realidad y, consecuentemente, plantear una reinterpretación del artículo octavo inciso primero del código del Trabajo, pasando desde

\footnotetext{
1 Entre otros; CAAMAÑo, E. "Análisis crítico sobre la aplicación de la doctrina de los actos propios en materia laboral", en: Revista de Derecho de la Pontificia Universidad Católica de Valparaiso XXXII, 2009, Santiago, Chile, 2008. UGARTE, J. "Los actos propios en materia laboral o guía de cómo inventarse una doctrina", en: Revista Laboral Chilena, Santiago, Chile, 2008.

2 Véase, por ejemplo, fallo CS rol 981-2005, 30de agosto 2006; fallo CS rol 913-2000, 27 de febrero 2000; fallo CS rol 771-2005, 25 de octubre 2006; fallo CS rol 2450-2005, 20 de diciembre 2006; fallo CS rol 5687-2006, 17 de octubre 2007; fallo CS 2320-2008, 10 de junio 2008; fallo CS rol 5129-2008, 4 de noviembre 2008.

3 La doctrina de los actos propios, nacida al alero del Derecho Civil, importa que entre contratantes iguales, las conductas pasadas de una de ellas, a la luz de la buena fe, pueden generar la expectativa en la otra, legítima y amparada por el Derecho, de que no se ejercerán derechos subjetivos en contradicción con dicha conducta. Se trata, en ese sentido, como lo ha entendido buena parte de la doctrina comparada, de una limitación al ejercicio de los derechos subjetivos. UGARTE, J. La subordinación en el Derecho Laboral Chileno. Santiago, Chile: Editorial LegalPublishing, 2008, p. 48.

4 Gumucio, J., Corvera, D. "Comentario a una jurisprudencia: La doctrina de los actos propios y el Derecho Laboral", en: Revista Laboral Chilena, ${ }^{\circ} 151$. Santiago, Chile, 2006, p. 72.

5 LAREnZ, K. Derecho de obligaciones. Madrid, España: Editorial Revista de Derecho Privado, 1958, p. 50.
} 
una presunción de laboralidad a una presunción simplemente legal de afectación de la voluntad, toda vez que con ello otorgaremos un diseño jurídico laboral al intérprete y sentenciador laboral, que debe decidir de acuerdo a Derecho si en estos casos difíciles se aplica o no el orden público laboral. Con todo, hacemos explícito que en todo momento tendremos en vista el caso de una relación regulada formalmente por un contrato civil con indicios de subordinación, excluyendo del estudio los casos donde la relación contractual se encuentra regulada por un contrato de trabajo o cuando la relación contractual no se encuentra regulada formalmente, toda vez que en estos dos últimos casos la aplicación tradicional de los indicios de subordinación resuelven correcta y lícitamente el problema, diferente al primer supuesto donde el querer declarado obliga a un necesario matiz como ya lo veremos.

\section{NATURALEZA JURÍDICA DEL PRINCIPIO DE PRIMACÍA DE LA REALIDAD}

\subsection{ENFOQUE TRADICIONAL DEL PRINCIPIO: LA PRÁCTICA POR SOBRE LAS FORMALIDA-} DES

La doctrina laboral, fuertemente acogida por nuestra jurisprudencia ${ }^{6}$, sostiene que el principio en estudio evidencia que en materia laboral ha de prevalecer siempre la verdad de los hechos por encima de los acuerdos formales:

"El significado de este principio es la primacía de los hechos sobre las formas, las formalidades o las apariencias. En materia laboral importa lo que ocurre en la práctica más que lo que las partes hayan pactado en forma más o menos solemne o expresa, - lo que luzca en documentos, formularios e instrumentos de control"7. "Demostrados los hechos, no pueden ser contrapesados o neutralizados por documentos o formalidades" 8 .

Con lo anterior, pareciera entonces, que el principio en estudio únicamente fortalece la relación que existe entre Derecho y realidad, esto es, aquello que queda resumido con el viejo adagio que las cosas son lo que son y no lo que dicen ser ${ }^{9}$ producto del poder de formalización e imposición de una de las partes en esta área del Derecho, no constituyéndose, como un principio exclusivo del Derecho del Trabajo.

\footnotetext{
6 A título de ejemplo citamos el ya clásico fallo CS rol 21950, 16 de marzo 1987 "Entre los principios imperantes en materia de Derecho del Trabajo, y que sirven de inspiración al Derecho positivo en esta rama, se encuentra el de primacía de la realidad, que significa que en caso de discordancia entre lo que ocurre en la práctica y lo que surge de los documentos o acuerdos, debe darse preferencia a lo primero, es decir, a lo que sucede en el terreno de los hechos (los Principios del Derecho del Trabajo. Américo Plá R.)"

7 PLA, A. Los principios del Derecho del Trabajo-3a edición-. Buenos Aires, Argentina: Editorial Depalma, 1998, p. 175.

8 Gamonal, S. Introducción al Derecho del Trabajo. Santiago, Chile: Editorial Jurídica ConoSur Ltda., 1998, p. 175.

9 La relación que existe entre Derecho y realidad, se puede comprender al observar que el Derecho es de esas cosas que pertenecen al mundo de la cultura, por ende tiene substrato real, pero su ser peculiar, su esencia, consiste en que poseen una significación constitutivo de expresiones humanas. RECASENS SICHES, L. Introducción al Estudio del Derecho. México: Editorial Porrúa S.A., 1996, p. 25.
} 


\subsection{REFORMULACION DEL PRINCIPIO: LAS CIRCUNSTANCIAS POR SOBRE LOS PRINCIPIOS ABSTRACTOS DE IGUAL LIBERTAD DE VOLUNTAD QUE INSPIRAN AL DERECHO PRIVADO MODERNO}

Comenzaremos diciendo como lo establece nuestra carta fundamental que en principio todos los hombres son libres, por lo tanto, merecen igual trato, idea que supone un desarrollo pleno de la concepción de igualdad formal, estructurándose el Derecho bajo la idea que:

“el individuo solo puede existir socialmente como personalidad cuando le sea reconocida por los demás no solo su esfera de la personalidad y de la propiedad, sino cuando, además, pueda en principio reglamentar por sí mismo sus cuestiones personales $y$, en tanto con ello quede afectada otra persona, pueda reglamentar sus relaciones con ella con carácter jurídicamente obligatorio mediante un concierto libremente establecido" 10 .

De esta manera, al ponerse de manifiesto "en el contrato la voluntad de ambos contratantes existe cierta garantía en el sentido de que lo que las partes han establecido como vinculante para ellas no es una pura arbitrariedad, sino que algo contemplado en su conjunto, es razonable y justo" 11 .

Esta concepción exige que el derecho privado sea regido por principios como la iniciativa privada y la libertad económica, los cuales otorgan un sitial especialmente relevante a la autonomía privada, entendida esta para efectos jurídicos "como el poder o facultad de los individuos para crear actos jurídicos o someterse a un estatuto legal o particular, si lo desean de esta forma, y regular los efectos del acto jurídico o someterse a un estatuto preexistente" 12 .

Sin embargo, el principio de primacía de la realidad que responde a una concepción de justicia social ${ }^{13}$, nos permite observar que los seres humanos están enfrentados a circunstancias muy dispares que afectan la libertad de contratación y, por ende, que el paradigma de la igual libertad de voluntad que satisface el estándar de justicia en la modernidad no es real ${ }^{14}$, al menos así lo ha establecido el legislador en materia laboral. De esta manera, el

10 LARENZ, K., op. cit. (n. 10), p. 65.

11 Ibid. Interesante resulta observar cuando este autor en igual lugar indica que "al ponerse ambas partes, por propia y libre voluntad, de acuerdo sobre determinadas prestaciones y obligaciones resultará que ninguna depende del arbitrio de la otra y ambas están en situación de velar así por su propio interés".

12 BARCIA, R. La autonomía privada como principio sustentador de la teoría del contrato y su aplicación en Chile. Santiago, Chile: Cuadernos de análisis jurídicos, colección de Derecho Privado III, Ediciones Universidad Diego Portales, Santiago, Chile, 2006 , p. 172.

13 Lo sostenido se induce de la fundamentación del principio de primacía de la realidad. Así, por ejemplo, Plá tiene entre los fundamentos la desigualdad económica y cultural de las partes. PLÁ, A., op. cit. (n. 7), p. 335. Entre nosotros, GAMONAL, S., op. cit. (n. 8), p. 176.

14 Como lo afirma Kant a la hora de explicar el concepto de libertad; las personas determinan su arbitrio con independencia de todos los condicionamientos empíricos (de lo sensible en general), lo que demuestra en las personas una voluntad pura. A pesar de lo anterior, Kant reconoce que nuestro arbitrio es afectado por la experiencia sensible, pero que lo determinante no es esta experiencia sino que las leyes prácticas incondicionadas, los imperativos categóricos. KANT, I. La metafisica de las costumbres. $-4^{\mathrm{a}}$ edición-. Madrid, España: Editorial Tecnos, 1989, pp. 26 y ss. 
principio en estudio se induce de la gran mayoría de las instituciones que forman el Derecho del Trabajo individual, en las cuales se plasma una desigualdad formal, en tanto esas instituciones reconocen que la voluntad de las personas contratantes se ve afectada por las circunstancias donde manifiestan su voluntad de contratación, obligando a un trato desigual, toda vez que es una máxima de justicia tratar igual a los iguales y desigual a los desiguales para evitar odiosos privilegios.

Antes de seguir debemos detenernos brevemente para fijar nociones respecto de libertad contractual y orden público, en tanto que sobre estas bases jurídicas se plantea el problema que se viene describiendo. En virtud de la primera

"las partes fijan el contenido y los efectos del contrato, poniéndose de manifiesto la función normativa del contrato, como creación de derecho objetivo. Sin perjuicio de ello las partes están limitadas por el ordenamiento jurídico e, incluso, por su propia voluntad, que puede estar vinculada por actos o contratos anteriores" 15 .

Mientras que el orden público se ha observado desde la óptica contractual como "una limitación a la autonomía privada impuesta por el Derecho, comprensivo de los principios jurídicos, públicos y privados, políticos, morales y económicos que son absolutamente obligatorios para la conservación del orden social en un pueblo y en una época determinada"16.

Ahora bien, el principio en estudio observa la realidad de las circunstancias materiales y como ellas repercuten en la libertad de la voluntad, permitiendo conocer cuando se está en una situación desigual que autorice el trato formalmente desigual, propio del Derecho del Trabajo. Derecho que regula el acto del trabajador que permite salir de la contingencia de precariedad en la que se situaba por no trabajar o del riesgo que lo afectaría si no trabajara, otorgando primacía a esta realidad por sobre los principios abstractos de libertad e igualdad de trato que inspiran al Derecho Privado moderno.

El principio de primacía de la realidad, al exigir observar la situación material en la que se encuentran las partes contratantes, evita los privilegios y asegura la equidad en el ordenamiento jurídico ${ }^{17}$, toda vez que la equidad nos permite corregir una injusticia emanada de la aplicación rígida de una regla o principio, cómo es el artículo 1560 del Código Civil ${ }^{18}$,

15 BARCIA, R., La autonomía... (n. 12), p. 173.

16 Dfez-PiCaso, L. y Guillón, A. Sistema de Derecho Civil. Madrid, España: Editorial Tecnos, 2002, p. 378.

17 "Mediante las conocidas características de la generalidad y de la abstracción, una ley, cualquiera que sea, asegura únicamente una primera forma de igualdad, la formal, entendida como tratamiento equitativo de quienes pertenecen al mismo rango. No por casualidad el principio general que prescribe el trato igual para los iguales (y el desigual para los desiguales) se llama regla de justicia". BOBBIO, N. Norberto Bobbio: el filósofo y la política (antología). México: Editorial Fondo de Cultura Económica, 1996, p. 207.

18 Contra la opinión de la mayoría, compartimos con BARCLA cuando sostiene que el artículo 1560 del CC parece inclinarse por la interpretación objetiva del contrato al preceptuar "conocida claramente la intención de los contratantes debe estarse a ella más que a lo literal de las palabras", a pesar de recepcionar nuestro Código Civil un sistema de interpretación contractual subjetivo. Así de ser claro el tenor del contrato y no existir antecedentes de peso, que den a entender que existe un consentimiento contrario, el juez debe abstenerse de interpretar, en virtud del brocardo in claris non fit interpretatio, asegurándose a su vez el respeto a la autonomía de la voluntad por parte de un tercero intérprete. Con todo, se presentan dos posiciones dentro de las doctrinas subjetivistas de interpretación. La primera señala que no se puede desatender lo escrito si es claro y la segunda, en cambio, sostiene que se puede desatender lo declarado aunque sea claro, pero solo si aparece una intención claramente en 
según lo veremos más adelante, o el derecho fundamental de igualdad ante la ley y, en segundo lugar, evita los privilegios al descubrir si existe o no desigualdad real, debido a que el ordenamiento, al tratar igual a los desiguales, beneficiaría a la parte que no está afectada por las circunstancias de precariedad al momento de manifestar su voluntad. Por otra parte, el principio en estudio trae como consecuencia no beneficiar a una de las partes con la normativa laboral, cuando estas son igualmente libres jurídicamente -estándar legislador democrático- al momento que han expresado su voluntad de obligarse ${ }^{19}$.

A mayor abundamiento, hoy en día la base del sistema económico es el intercambio o la conmutatividad del ordenamiento jurídico, fundado en el llamado principio de equilibrio de las prestaciones, el cual manifiesta "la misión social" del Derecho Privado cuando vela por el equilibrio de las prestaciones, esto era constatado por Larenz cuando indicaba que el Derecho Privado debía establecer condiciones y dictar normas que hagan posible un equilibrio razonable de las fuerzas sociales y de los intereses de un grupo humano y tomen en consideración la necesidad de protección de los económicamente débiles ${ }^{20}$.

\section{SENTIDO Y ALCANCE DEL ARTÍCULO OCTAVO DEL CÓDIGO DEL TRABAJO}

\subsection{PRESUnCión de LABORALIDAD}

Mientras que de la redacción del artículo séptimo del código del ramo se pueden observar cuáles son los elementos esenciales del contrato de trabajo ${ }^{21}$, en el artículo siguiente, inciso primero, se nos indica expresamente que la concurrencia copulativa de tales elementos hace presumir la existencia de un contrato de trabajo ${ }^{22}$. Ahora bien, genera extrañeza que el legislador realice esta declaración, pues parece de toda lógica y conocimiento del Derecho que en un contrato en el cual concurran sus elementos esenciales inmediatamente se configura el tipo contractual. Dicho de otra forma, sería absurdo que en un contrato de compraventa existan sus elementos esenciales y no se configure una compraventa.

Por lo tanto, y basados en la regla de hermenéutica legal del legislador perfecto, sostenemos que en el artículo octavo, inciso primero, nos enfrentamos realmente a una presunción de afectación de libertad para contratar, que produce como efectos excepcionar la regla de hermenéutica de los contratos radicada en el artículo 1560 del Derecho general

\footnotetext{
otro sentido. Siendo esta última la que debería primar entre nosotros como se desprende de la nota dejada por Bello en el artículo 1560 "en los contratos, es de regla atenerse a la letra en lo que no pugna manifiestamente con la conocida intención de los contratantes.". Ver BARCIA, R. Lecciones de Derecho Civil Chileno. Tomo I y II. Santiago, Chile: Editorial Jurídica de Chile, 2007, pp. 23 y ss.

19 Asunto que acontece con la interpretación pacífica en nuestra doctrina sobre el artículo octavo, inciso primero, del Código de Trabajo, que exige para la aplicación del orden público laboral únicamente el elemento de subordinación o dependencia en la relación contractual.

20 LARENZ, K., op. cit. (n. 10), p. 14.

21 Artículo séptimo Código del Trabajo: "Contrato individual de trabajo es una convención por la cual el empleador y el trabajador se obligan recíprocamente, este a prestar servicios personales bajo dependencia y subordinación del primero, y aquel a pagar por estos servicios una remuneración determinada".

22 Artículo octavo Código del Trabajo: "Toda prestación de servicios en los términos señalados en el artículo anterior, hace presumir la existencia del contrato de trabajo...".
} 
y común ${ }^{23}$, precisamente para otorgar elementos al intérprete decisor cuando se enfrente principalmente a los casos difíciles planteados más arriba, a saber: una relación contractual perdurable con bajo estándar de subordinación, pero formalizada bajo un tipo civil, donde el pretensor conocía las expectativas de la contraria y ejercía sus derechos civiles subjetivos.

De esta manera, sostenemos, desde una perspectiva tradicional, que sin la existencia del artículo octavo, el intérprete llamado a pronunciarse sobre la naturaleza jurídica de la relación contractual que plantea la controversia, debiera estarse a los hechos reveladores de la intención de las partes y observar si de ellos se desprenden los elementos esenciales del contrato según prescribe el mismo artículo 1560 del Código Civil, por lo tanto, en silencio de la normativa laboral sobre el respecto se llegaría a idénticos resultados que los otorgados por la doctrina al artículo en cuestión, no siendo necesario tal precepto ${ }^{24}$.

\subsection{PRESUNCIÓN DE AFECTACIÓN DE LIBERTAD JURÍDICA MÍNIMA PARA CONTRATAR} CON IGUAL LIBERTAD. CONSECUENCIAS PARA EL PROBLEMA QUE SE PLANTEA: EXCEPCIÓN A LAS REGLAS GENERALES DE HERMENÉUTICA CONTRACTUAL Y APARENTE MATIZ AL PRINCIPIO DE BUENA FE

La realidad como reveladora de la intención de las partes es importante para conocer el verdadero acto que se constituyó con la declaración de la voluntad y, de esa manera, salir muchas veces del error en que se encontraba el actor o las partes, por ello, este examen opera sobre la faz cognitiva de la voluntad, como muchas veces lo evidenciamos en la denominación errónea que se da al contrato. Sin embargo, el principio de primacía de la realidad opera sobre el elemento volitivo del acto, porque permite superar el querer aparente y declarado de las partes celebrantes del contrato de trabajo, en atención a la afectación que produce en su libre arbitrio las circunstancias materiales, incluso, conociendo el afectado, gravemente la naturaleza jurídica real del contrato celebrado.

Por lo tanto, el artículo octavo que cristaliza el principio de primacía de la realidad ${ }^{25}$, permite indagar y declarar al intérprete de una relación contractual, cuando una de las partes tiene una libertad extremadamente disminuida por las circunstancias materiales que lo afectan -incluso cuando las partes del contrato en el cual se evidencian los elementos esenciales del contrato de trabajo declaran que han consentido en celebrar un contrato distintoque igualmente será un contrato de trabajo.

\footnotetext{
23 El artículo 1560 del Código Civil impide que el juez pueda interpretar contra la voluntad declarada y clara de las partes, limitando la interpretación a la voluntad claramente conocida de los contratantes, por lo tanto, si el juez entra a interpretar una cláusula clara y precisa atribuyendo un sentido diversa viola el artículo $1560 \mathrm{CC}$. cuando señala "conocida claramente la intención de los contratantes", toda vez que cuando es claro el tenor del contrato y no existen antecedentes de peso, que den a entender que existe un consentimiento contrario, el juez debe abstenerse de interpretar. De esta manera, pareciera que el tenor literal del artículo en cuestión establece una interpretación objetiva limitada de los contratos que obliga a observar la voluntad declarada si esta es clara, en el contexto de los sistemas de interpretación subjetivos decimonónicos. Ver BARCIA, R., Lecciones... (n. 18).

24 Parte de la doctrina ya ha visualizado que "dicha norma (artículo $8^{\circ}$ ) no hace sino que reforzar la idea del artículo citado (artículo $7^{\circ}$ ) en el sentido de que verificado los elementos de una relación laboral, debe entenderse, no presumirse, la existencia de un contrato de trabajo". UGARTE, J. El nuevo Derecho del Trabajo. Santiago: Editorial LegalPublishing, 2007 , p. 62.

25 RoJAS, I. Manual de Derecho del Trabajo. Santiago, Chile: Editorial LexisNexis, 2004, p. 23.
} 
En este orden de ideas, salta a la vista la importancia y efectos del artículo octavo inciso primero, toda vez que se constituye en una excepción al artículo 1560 del Código Civil ${ }^{26}$, el cual obliga al intérprete a estarse, en una relación entre privados, a la intención que declaran las partes, puesto que las partes al estar en una igual libertad para contratar, declararán, si no están en un error, estar celebrando el contrato que su libre arbitrio quiere. En otras palabras, el artículo 1560 nos dice que la intención que declaran las partes es efectivamente lo que quieren y a la cual debemos estarnos para no violar el principio de la autonomía de la voluntad ${ }^{27}$, salvo que exista un vicio de la voluntad o, derechamente, una voluntad fuertemente constreñida por las circunstancias materiales como acontece y autoriza el Derecho del Trabajo a través del principio de primacía de la realidad regulado en el artículo octavo en comento.

De esta manera, se desprende razonablemente que el querer declarado por el prestador de servicios personales no forma necesariamente expectativas confiables en su contraparte, en tanto sabe este último que lo declarado se encuentra afectado por las circunstancias materiales donde se desenvuelve la voluntad.

No es admisible la recepción de la doctrina de los actos propios para proteger al que contrató los servicios personales ${ }^{28}$, toda vez que sus expectativas, respecto de la relación jurídica, no se determinan en principio si hay subordinación por lo declarado por el prestador de servicios personales, al existir una razonable voluntad afectada por las circunstancias socioeconómicas, salvo que este pruebe que desconocía la afectación de la voluntad, lo cual es improcedente si sabe -a menos que se acoja excepción de error esencial- que existen indicios de subordinación ${ }^{29}$, elemento que hace presumir la afectación de la voluntad, pudiéndose probar aún, que aunque el empleador sepa que existe subordinación, la voluntad declarada no estaba afectada por las circunstancias económicas. Aconteciendo, entonces, que la buena fe del acreedor de servicios personales no se afecta por no decidir en atención a

26 Para Barcia el artículo 1560 establece una restricción consistente en impedir que el juez pueda interpretar contra la voluntad declarada y clara de las partes. BARCIA, R., Lecciones... Tomo II (n. 18), p. 23. En igual sentido, López Santa María sostiene que el código civil limita la interpretación, contra lo expresamente declarado, a la voluntad claramente conocida de los contratantes. LÓPEZ, J. Los contratos. Parte General. Santiago, Chile: Editorial Jurídica de Chile, 1986, p. 312.

27 El proceso de interpretación del contrato más allá de la interpretación de los hechos, contiene una operación de Derecho, resaltando en esta la calificación jurídica del mismo, donde una ilícita actuación del Tribunal permite la admisibilidad del recurso de casación, ya sea por la errada calificación jurídica de un contrato, ya sea por la desnaturalización de una cláusula clara y precisa. Asunto este último que ocurriría en nuestro caso cuando el tribunal determinara que existe un contrato de trabajo. Sin embargo, el artículo octavo inciso primero excluye la regla de orden público contenida en el artículo 1560 del código civil que prohíbe al tribunal interpretar frente a declaraciones claras.

28 Además de compartir los argumentos jurídicos formales para la improcedencia de la doctrina de los actos propios en el Derecho del Trabajo para justificar la exclusión del orden público laboral, esto es; "Para que opere el acto propio como límite del derecho subjetivo de una de las partes es imprescindible que la conducta anterior que ha generado la expectativa legítima de mantenerse, sea eficaz jurídicamente hablando". UGARTE, J. La subordinación en el Derecho Laboral Chileno. Santiago, Chile: Editorial LegalPublishing, 2008, p. 48.

29 Siguiendo a Palomeque López, habrá subordinación si el que trabaja no organiza su trabajo, sino que lo presta bajo órdenes de otro, que tiene el poder de especificar el contenido y las cualidades del trabajo y orientar hacia un resultado la actividad. Palomeque, M. Derecho del Trabajo e ideologia. Madrid, España: Editorial Tecnos, 2002. 
los puros elementos declarados o actuados, pues, por regla general, de buena fe él conocía su calidad de empleador ${ }^{30}$.

Lo anterior, además, está en plena coherencia con el pilar de la seguridad jurídica, toda vez que en:

"el mundo de los negocios jurídicos, merece protección la confianza razonable suscitada objetivamente por una situación jurídica: que quien de buena fe realiza un negocio jurídico fundado en la confianza razonable que objetivamente le suscita una situación de apariencia creada o mantenida por otra persona, debe ser protegido aunque de ello resulte un sacrificio para el interés o para el derecho de otro" 31 .

Por consiguiente, el artículo octavo, inciso primero, del Código del Trabajo, viene a señalar que al existir el elemento de subordinación o dependencia ${ }^{32}$-que nos muestra, por regla general, la desigual libertad para contratar de las partes- el "querer" del afectado por las circunstancias está constreñido, hasta tal punto que no puede considerarse su declaración y actos de que no está celebrando un contrato de trabajo.

Consideramos que sí se establece una presunción en el artículo octavo y no solo un refuerzo de la idea de laboralidad, toda vez que nuestro legislador manda a presumir de un hecho conocido, la subordinación y/o dependencia, deducir el hecho desconocido, la afectación de la voluntad de una de las partes contratantes por las circunstancias en que se encuentra. Presunción que permitirá la aplicación del orden público laboral en la relación declarada por las partes como civil, sabiendo el pretensor su naturaleza jurídica laboral, salvo prueba en contrario que acredite que el pretensor no tenía una voluntad de contratación fuertemente afectada por las circunstancias que determinara una desigualdad real, capaz de autorizar el trato desigual del orden público laboral.

Lo recientemente expuesto viene a demostrar que el elemento de subordinación o dependencia se constituye como una manifestación del principio de primacía de la realidad, pero no como un instrumento para el descubrimiento de la relación existente según su función tradicional, sino que es gracias a la constatación del elemento peculiar del contrato de trabajo que ponemos en movimiento al principio de primacía de la realidad. Es el sustrato de afectación de la voluntad de una de las partes contratantes observada por el intérprete inspirado en el principio de primacía de la realidad, lo que legitima y valida la aplicación del orden público laboral en una relación declarada por las partes sin error como civil, salvo prueba en contrario.

\footnotetext{
30 TAPIA, F. "Trabajo subordinado y tutela de los derechos fundamentales", en: AA.VV. La subordinación o dependencia en el contrato de trabajo. Santiago, Chile: Editorial LexisNexis, 2005, p. 232.

31 Díez-PICASO, L. Fundamentos del Derecho Civil patrimonial. -5a edición-. Madrid, España: Editorial Civitas, 1996, p. 54.

32 Barassi atribuye al elemento de subordinación o dependencia una doble función; configurador del contrato de trabajo y determinante para la aplicación de la legislación social. En igual sentido, entre nosotros, Macchiavello reconocerá el doble rol de esta categoría, en cuanto se refiere al modo en que se debe llevar a cabo la relación laboral y en cuanto impone a las partes de la relación laboral un conjunto de derechos y obligaciones. En: DOMínGUEz, Carmen Elena. Apuntes de clases. Diplomado Derecho del Trabajo y la Seguridad Social. Pontificia Universidad Católica de Chile, 2010.
} 
Es necesario dejar en claro que nuestra propuesta corre por cuerda separada a un eventual vicio del consentimiento, que factiblemente puede operar en el supuesto en estudio, particularmente un error esencial $\mathbf{u}$ obstáculo en la causa ${ }^{33}$, de una o de ambas partes del contrato celebrado, toda vez que en estos casos existe ignorancia de los hechos reales por la o las partes contratantes -probablemente se alegará por el empleador, como excepción, desconocimiento de subordinación, asunto que le resultará muy difícil de probar por la naturaleza de tracto sucesivo de la prestación de servicios y su materialidad-. En cambio, nuestro problema radica en que efectivamente existe subordinación conocida por las partes, donde, en principio, se aplicará el orden público laboral, en tanto se presume la afectación de la voluntad del trabajador, pero ello admite prueba en contrario.

En consecuencia, el supuesto de aplicación en estudio admite como todo acto jurídico un problema de error obstáculo o esencial; sin embargo, ello se dará en un primer grado, cuando existe ignorancia sobre las causas inmediatas del acto jurídico -como ya se dijo-, probablemente en nuestro caso mediante una excepción de error esencial por parte del empleador alegando desconocimiento de subordinación, por mientras que nosotros, en un segundo grado, atacamos el supuesto bajo la condición que el empleador conoce los indicios de subordinación, pero se quiere liberar de la aplicación del orden público laboral mediante la prueba de una inexistente afectación de voluntad para contratar en términos de igualdad jurídica mínima, ya que producto de la subordinación se presume tal afectación de voluntad.

Así las cosas, el principio de primacía de la realidad permite identificar, más allá de la subordinación, si las partes contratantes están o no en una situación de igual libertad contractual y, de esta manera, determinar el tratamiento que se dará a la relación contractual declarada formalmente por las partes, con bajo estándar de subordinación y por largo tiempo como civil, toda vez que el querer declarado carecerá de valor si las circunstancias del afectado eran apremiantes y conformaban una desigualdad que obligaba a una tratamiento normativo diverso.

Los argumentos que se sostienen, siempre tienen en vista el querer civil declarado y actuado, no la omisión formal o la relación declarada laboralmente, ya que esto último se salva con lo prescrito por el artículo séptimo del código del ramo al igual que cuando el contrato declarado es civil por error de las partes. Teniendo el artículo octavo, inciso primero, como función excepcionar en materia laboral la regla de hermenéutica del artículo 1560 del Código Civil, al permitir al intérprete superar la intención declarada por el trabajador, declarando que el contrato es de naturaleza laboral, salvo prueba en contrario por constituirse en una presunción simplemente legal según las reglas generales de nuestro Derecho, lo prescrito en el artículo octavo del Código del ramo.

\footnotetext{
33 El Código Civil, en su artículo 1453, señala dos casos de error esencial. El primero es aquel que "recae sobre la especie de acto o contrato que se ejecuta o celebra, como si una de las partes entendiese empréstito y la otra donación". El segundo caso es aquel en que recae "sobre la identidad de la cosa específica de que se trata, "como si en el contrato de venta el vendedor entendiese vender cierta cosa determinada, y el comprador entendiese comprar otra". DuCCI, C. Derecho Civil. Parte General. Santiago, Chile: Editorial Jurídica de Chile, Santiago, 2005, p. 259. De esta manera, existen dos tipos de errores obstáculos, en la causa y en el objeto, siendo el primero de interés para este trabajo, en tanto es el que recae sobre la especie o naturaleza del acto o contrato. "Este error recae directamente en la causa que induce a la celebración del acto o contrato". Ver BARCIA, R., Lecciones... Tomo I (n. 18), p. 53.
} 


\section{RIESGOS DE REVISIÓN JUDICIAL EN EL ACTUAL RAZONAMIENTO JURISPRUDENCIAL}

En el mismo sentido de denunciar las actuales decisiones judiciales, carentes de categorías dogmáticas laborales que permitan explicar en Derecho la aplicación o no del orden público laboral, nuestros tribunales han entrado a conocer estas relaciones jurídicas, formalmente civiles con bajo estándar de subordinación, escondiendo no pocas veces una verdadera revisión judicial al contrato, lo cual es inadmisible en nuestro Derecho sustentándonos en el artículo 1545 del Código Civil -como se ha dicho reiteradamente por nuestra doctrina con ocasión del tratamiento a la teoría de la imprevisión- porque en dicho artículo se consagra el principio pacta sunt servanda, materializando la intangibilidad absoluta de los contratos. Además, es recurrente que se sentencie tradicionalmente que nuestro Derecho se apoya en la teoría clásica del contrato ${ }^{34}$, la cual posiciona a la autonomía de la voluntad formal en un sitial intocable como se ha venido sosteniendo más arriba, argumentándose que la revisión del contrato crea una gran incertidumbre en el cumplimiento de este, rememorándose para ello la vieja práctica que generó la figura de la cláusula rebus sic stantibus, antecedente histórico de la revisión de los contratos ${ }^{35}$.

En este orden de ideas el diseño jurídico que se plantea, permite salvar el riesgo de revisión judicial existente en la actual forma de razonar de los tribunales, en tanto se observan categorías dogmáticas que conforman un diseño necesario y suficiente para circunscribir la decisión judicial a un asunto de interpretación y calificación jurídica del acto al momento de celebrarlo y no elementos de argumentación que ponen el acento en la situación socioeconómica de una de las partes al momento de producirse el conflicto jurídico, en tanto esto último ha venido a transformar la decisión judicial en una especie de revisión judicial.

En este sentido, los Tribunales de Justicia han entrado a conocer y sostener sus decisiones sobre la problemática en estudio en razones de buena fe. Ahora, si bien es cierto que se plantea en parte de nuestra doctrina que la buena fe es un elemento que justifica la intervención del contrato sustentada en la teoría del negocio jurídico, producto de fallar la base del negocio, no es menos cierto que el estatuto regulatorio del contrato de trabajo, tiene en vista la fuerte función social del contrato, por ende, ante eventuales revisiones judiciales sería más pertinente explicarlo desde la teoría de la sustentación económica, caracterizada por admitir la revisión del contrato.

La revisión judicial se produciría porque esta teoría concibe que la causa del negocio jurídico es la "función económico-social que caracteriza al tipo de negocio como acto de autonomía privada y determina su contenido mínimo necesario" 36 , por ende, "la causa debe responder también a una exigencia duradera de la vida de relación, a una función de interés social que solo el Derecho es competente para valorar en su idoneidad para justificar positi-

\footnotetext{
34 BARCLA, R., La autonomia... (n. 12), p. 172.

35 BARCIA, R. "Breve análisis de la teoría de la imprevisión en el derecho chileno bajo la perspectiva del análisis económico", en: Estudios de Derecho Civil. Libro en bomenaje a José Luis Aguilar Gorrondona. Tomo I. Caracas, Venezuela, 2002, pp. 195 y 208.

36 BETTI, E. Teoría general del negocio juridico. Granada, España: Editorial Comares, 2000, p. 177.
} 
vamente su tutela" 37 . De esta manera, para encontrar la autonomía privada reconocida por el Derecho no basta la licitud -en sentido estricto, violación de norma de orden público "típica cerrada"- de la misma, sino que debe responder la normativa a la función económicosocial a la cual se ha dirigido el negocio.

Así, en nuestra opinión, en las actuales decisiones judiciales nos enfrentamos realmente ante revisiones judiciales, que se explican bajo la teoría de la sustentación económica, donde la decisión sobre el contrato consiste en observar si la normativa responde a la función socioeconómica del tipo que configura. Teoría nada más lejana de nuestro diseño dogmático que se sustenta en la teoría clásica del contrato.

En consecuencia, nos planteamos en forma crítica a esta revisión judicial, en tanto significa una alteración del mecanismo de distribución de riesgos definido ex ante por las partes y que será ajustado ex post por el Tribunal, echando mano en el caso en estudio aparentemente a la buena $\mathrm{fe}^{38}$, lo cual para nosotros se explica de mejor forma a través de la teoría de sustentación económica del contrato. Sin embargo, nuestra propuesta de solución a los problemas judiciales de este trabajo, pone el acento en la afectación de la voluntad al momento de celebrarse el acto, tornándose en un proceso de interpretación y calificación jurídica que determinará el estatuto predefinido legalmente que regula la relación privada, siendo lo anterior coherente con el principio de conservación de los contratos.

\section{DISCUSIONN}

La argumentación e interpretación que hemos sostenido, reinterpretando el principio de primacía de la realidad, como también la cobertura jurídico normativa que proponemos para resolver el conflicto eminentemente laboral que se plantea, nos permite presentar un principio exclusivamente laboral de primacía de la realidad acorde con el cuerpo normativo que tiene su ámbito de aplicación en las relaciones laborales y, con ello, superar una vacía e inocua "presunción de laboralidad" que nuestra doctrina laboral ha atribuido al artículo octavo, inciso primero, del Código del Trabajo. Alcanzándose, entonces, una presunción simplemente legal de afectación de voluntad para contratar con una igualdad jurídica mínima, que permita superar lo claramente declarado por las partes sin vicio del consentimiento.

En este orden de ideas, se cumple con las exigencias que la modernidad ha impuesto al Derecho y se otorga a los Tribunales un camino para fallar en Derecho, y no según el color de zapato de las partes, calificando el acto jurídico y declarando solamente los derechos nacidos de la autonomía de la voluntad de los particulares.

Con todo, no nos deja de seducir la propuesta al observar sus propiedades para proteger la parte más débil de la relación laboral -función finalista del Derecho del Trabajo- sin dejar de disminuir la eficacia del acto con un estándar de certeza propio de un Estado de Derecho.

37 Ibid.

38 BANFI, C. "Notas sobre la excesiva onerosidad sobreviniente en Derecho Privado Comparado", en: Revista Chilena de Derecho Privado Fernando Fueyo Laneri, no 6, Santiago, Chile, 2006, p. 49. 


\section{BIBLIOGRAFÍA}

BANFI, C. "Notas sobre la excesiva onerosidad sobreviniente en Derecho Privado Comparado", en: Revista Chilena de Derecho Privado Fernando Fueyo Laneri, n 6 , Santiago, Chile, 2006.

BARCIA, R. La autonomia privada como principio sustentador de la teoria del contrato y su aplicación en Chile. Santiago, Chile: Cuadernos de análisis jurídicos, colección de Derecho Privado III, Ediciones Universidad Diego Portales, Santiago, Chile, 2006.

BARCIA, R. "Breve análisis de la teoría de la imprevisión en el derecho chileno bajo la perspectiva del análisis económico", en: Estudios de Derecho Civil. Libro en homenaje a José Luis Aguilar Gorrondona. Tomo I. Caracas, Venezuela, 2002.

BARCIA, R. Lecciones de Derecho Civil Chileno. Tomo I y II. Santiago, Chile: Editorial Jurídica de Chile, 2007.

BETTI, E. Teoría general del negocio jurídico. Granada, España: Editorial Comares, 2000.

Boвbio, N. Norberto Bobbio: el filósofo y la política (antología). México: Editorial Fondo de Cultura Económica, 1996.

CAAMAÑo, E. "Análisis crítico sobre la aplicación de la doctrina de los actos propios en materia laboral", en: Revista de Derecho de la Pontificia Universidad Católica de Valparaiso XXXII, 2009, Santiago, Chile, 2008.

DfEZ-PICASO, L. Fundamentos del Derecho Civil patrimonial - $5^{\text {a }}$ edición-. Madrid, España: Editorial Civitas, 1996.

Díez-PiCaso, L. y Guillon, A. Sistema de Derecho Civil. Madrid, España: Editorial Tecnos, 2002.

DOMf́ngueZ, Carmen Elena. Apuntes de clases. Diplomado Derecho del Trabajo y la Seguridad Social. Pontificia Universidad Católica de Chile, 2010.

DuCCI, C. Derecho Civil. Parte General. Santiago, Chile: Editorial Jurídica de Chile, Santiago, 2005.

Gamonal, S. Introducción al Derecho del Trabajo. Santiago, Chile: Editorial Jurídica Conosur Ltda., 1998.

Gumucio, J., CoRvera, D. "Comentario a una jurisprudencia: La doctrina de los actos propios y el Derecho Laboral", en: Revista Laboral Chilena, n 151. Santiago, Chile, 2006.

KANT, I. La metafisica de las costumbres -4a edición-. Madrid, España: Editorial Tecnos, 1989.

LARENZ, K. Derecho de obligaciones. Madrid, España: Editorial Revista de Derecho Privado, 1958.

LOPEZ, J. Los contratos. Parte General. Santiago, Chile, Editorial Jurídica de Chile, 1986.

Palomeque, M. Derecho del Trabajo e ideología. Madrid, España: Editorial Tecnos, 2002.

PLA, A. Los principios del Derecho del Trabajo -3a edición-. Buenos Aires, Argentina: Editorial Depalma, 1998.

RECASENS SICHES, L. Introducción al Estudio del Derecho. México: Editorial Porrúa S.A., 1996.

ROJAS, I. Manual de Derecho del Trabajo. Santiago, Chile: Editorial LexisNexis, 2004.

TAPIA, F. "Trabajo subordinado y tutela de los derechos fundamentales", en: AA.VV. La subordinación o dependencia en el contrato de trabajo. Santiago, Chile: Editorial LexisNexis, 2005.

UGARTE, J. El nuevo Derecho del Trabajo. Santiago: Editorial LegalPublishing, 2007.

UGARTE, J. "Los actos propios en materia laboral o guía de como inventarse una doctrina", en: Revista Laboral Chilena, Santiago, Chile, 2008.

UGARTE, J. La subordinación en el Derecho Laboral Chileno. Santiago, Chile: Editorial LegalPublishing, 2008.

WEBER, M. Sociologia del Derecho. Granada, España: Editorial Comares, 2001. 